\begin{tabular}{|c|c|}
\hline Title & EVALUATION OF TSUNAMI FORCE ACTING ON BRIDGE GIRDERS \\
\hline Author(s) & MARUYAMA, K.; TANAKA, Y.; KOSA, K.; HOSODA, A.; ARIKA WA, T.; MIZUTANI, N.; NAKAMURA, T. \\
\hline Citation & $\begin{array}{l}\text { Proceedings of the Thirteenth East A sia Pacific Conference on Structural Engineering and Construction (EA SEC-13), } \\
\text { September 11-13, 2013, Sapporo, Japan, Keynote Lecture 3., Keynote Lecture } 3\end{array}$ \\
\hline Issue Date & $2013-09-11$ \\
\hline Doc URL & http:/hdl .handle.net/2115/54508 \\
\hline Type & proceedings \\
\hline Note & $\begin{array}{l}\text { The Thirteenth East A sia Pacific Conference on Structural Engineering and Construction (EA SEC-13), September 11- } \\
\text { 13, 2013, Sapporo, Japan. }\end{array}$ \\
\hline File Information & KeynoteLecture_3.pdf \\
\hline
\end{tabular}

Instructions for use 


\title{
EVALUATION OF TSUNAMI FORCE ACTING ON BRIDGE GIRDERS
}

\author{
K. MARUYAMA ${ }^{1 *}$, Y. TANAKA ${ }^{1}$, K. KOSA ${ }^{2}$, A. HOSODA $^{3}$, T. ARIKAWA ${ }^{4}$, \\ N. MIZUTANI ${ }^{5}$ and T. NAKAMURA ${ }^{6}$ \\ ${ }^{1}$ Department of Civil and Environmental Engineering, Nagaoka University of Technology, Japan \\ ${ }^{2}$ Department of Civil and Architectural Engineering, Kyushu Institute of Technology, Japan \\ ${ }^{3}$ Faculty of Urban Innovation, Yokohama National University, Japan \\ ${ }^{4}$ Coastal and Ocean Engineering Field, Port and Airport Institute, Japan \\ ${ }^{5}$ Graduate School of Engineering, Department of Civil Engineering, Nagoya University, Japan \\ ${ }^{6}$ Designated Lecturer, Institute for Advanced Research, Nagoya University, Japan
}

\begin{abstract}
This paper deals with what tsunami force acted on bridge girders by Great East Japan Earthquake broken out in March 11, 2011. First of all, a lot of efforts were conducted to collect almost all data of bridge girders in the inundation area. Satellite images in internet websites proved effective to make a quick survey of any bridge in the inundation area. For damage analysis the detailed data of bridges were collected through authorities. The method proposed by Prof. Kosa was introduced to see whether bridges were washed away or not by tsunami. The resistance of bridge is expressed as a function of the self-weight of bridge girder, and the force due to tsunami is defined by hydro-dynamic equation. More than two hundred bridges, including both washed away bridges and survived ones, were analyzed by the method. The damage analysis showed the importance of characteristics of tsunami, such as velocity and height in the land. Then, motion pictures taken during attack of tsunami were examined to evaluate the velocity and height of tsunami in the land. When bridges in a limited area were taken into account, the method was effective to see whether bridges were survived or not. Field survey showed that bridges washed away by tsunami should have had uplift force by tsunami. Experimental investigation was done using a water channel in different scales to examine what forces acted on bridge girders and to develop a proper simulation model.
\end{abstract}

Keywords: Tsunami, bridge girders, washed away, satellite images, damage analysis, simulation.

\section{INTRODUCTION}

Great East Japan Earthquake in March 11, 2011 caused the greatest tsunami we have ever had in one thousand years in Japan. Comparing the damage by the earthquake itself, the damage by the tsunami was much serious for our modern life in the area of eastern Japan.

\footnotetext{
* Corresponding author: Email: kmaru@vos.nagaokaut.ac.jp
} 
It was a shocking scene that a lot of bridges near the shore were washed away while very few bridges inland suffered from the earthquake. Since the Great Hanshin Earthquake in 1995, bridge engineers and researchers have been working hard on how to improve the seismic design of bridge structures. The damage of bridge by tsunami was completely out of our concerns because we have never had such damage since modern bridge technology has been introduced in one hundred years. Right after the earthquake, JSCE has set up a research committee on the tsunami force acting to bridges, consisting of members from various fields such as bridge engineering, concrete engineering, structural engineering and coastal engineering. The authors have been involved in the committee as directive members. This paper is a kind of mid-term report on what we have studied in one and a half years.

\section{DAMAGE OF BRIDGES BY TSUNAMI}

At the first stage any data of bridges which located in the inundation area from Aomori prefecture in the north to Chiba prefecture in the south were collected by both internet media and on site survey. Fig. 1 shows satellite images taken before and after the earthquake.

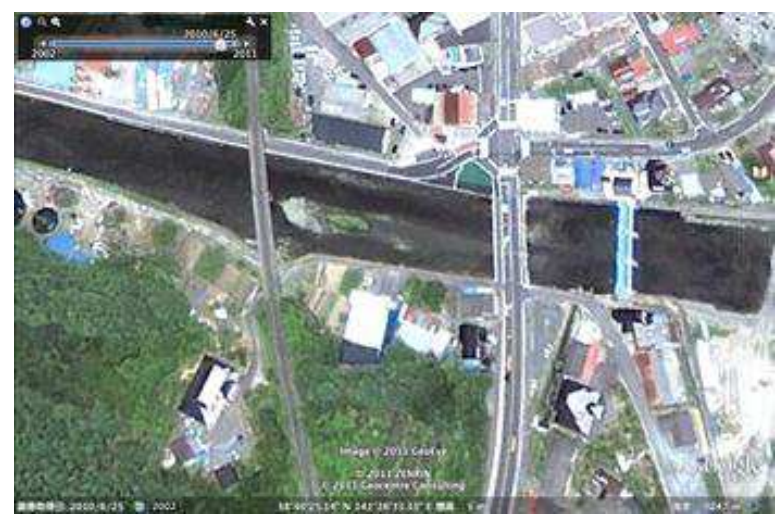

(a) Before Earthquake $\left(25^{\text {th }}\right.$ June, 2010)

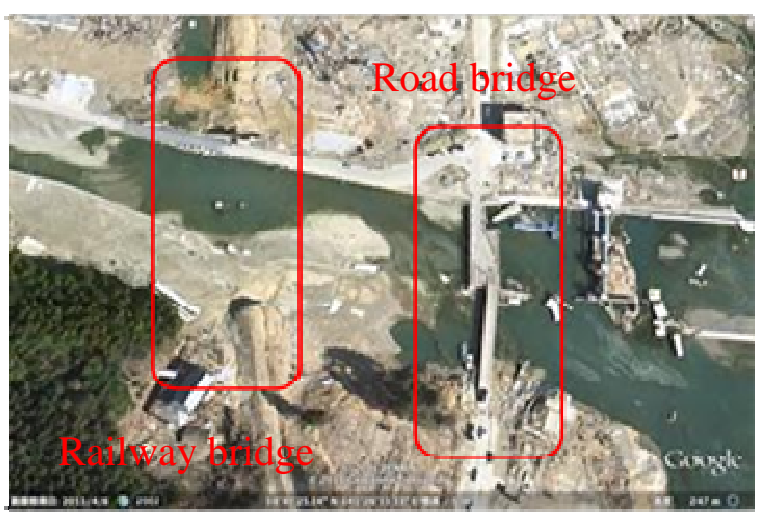

(b) After Earthquake (6 ${ }^{\text {th }}$ April, 2011)

Figure 1: Satellite images

Field survey was conducted several times to confirm the details of bridges. Finally, the statistic data are summarized as indicated in Table 1. The total number of bridges within the inundation area was 1,793 and the number of washed away bridges was 252, including 28 of railway bridges and 40 of major road bridges.

Table 1: Number of bridges in the area of inundation

\begin{tabular}{|l|c|c|c|c|c|c|}
\hline Pref. & Iwate & Miyagi & Fukushima & Ibaraki & Chiba & Total \\
\hline $\begin{array}{l}\text { Washed away } \\
\text { or moved }\end{array}$ & 78 & 102 & 68 & 2 & 2 & 252 \\
\hline Unclear & 0 & 0 & 8 & 0 & 0 & 8 \\
\hline Survived & 427 & 692 & 384 & 30 & - & 1533 \\
\hline Total & 505 & 794 & 460 & 32 & 2 & 1793 \\
\hline
\end{tabular}


In order to analyze the damage of bridges, the data of each bridge, such as type, dimension and structural details were collected from authorities who take care of bridges. Currently, the data of more than 400 bridges are collected and the database is now processed. Using the database, some trials have started to categorize bridges by their types and dimensions to see what a key is for resisting tsunami. Fig.2 shows the number of bridges with or without suffering from washed away in comparison with categorized items, such as type of bridge and bridge length. In the figure, only the survived bridges located near the washed away bridges are selected for comparison.

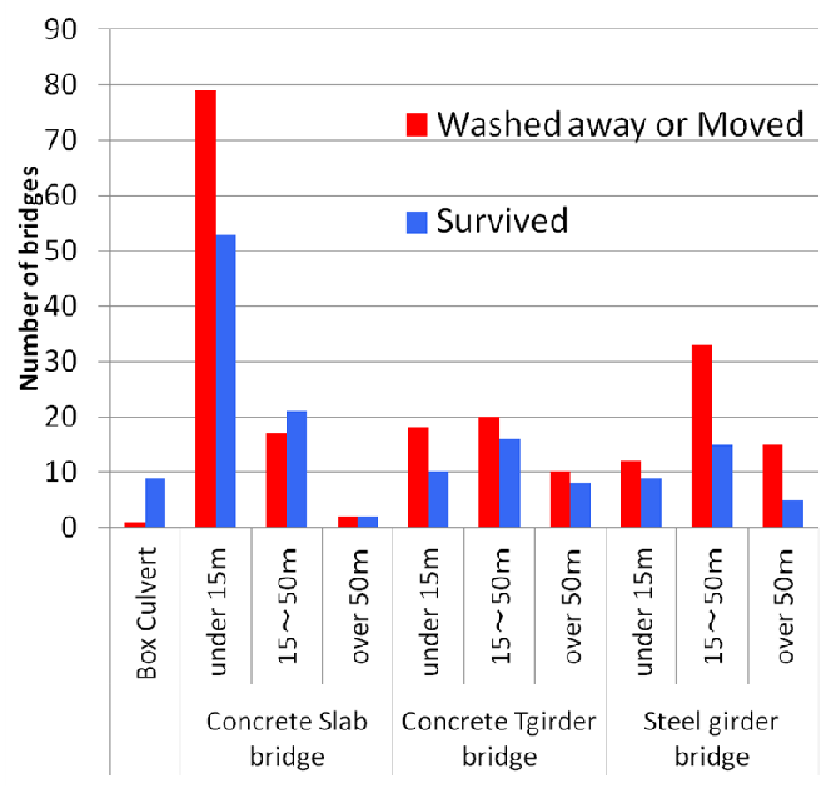

Figure 2: Damage analysis of bridge girders

Fig. 2 may not give us a clear tendency on what influences the damage of bridge. This is because no consideration is taken for the velocity and the height of tsunami at the location of bridge.

\section{EVALUATION OF GIRDER RESISTANCE AGAINST TSUNAMI}

Kosa (2010), one of the authors, has already started the investigation on the tsunami force acting on bridge girders after surveying the damage of bridges due to the tsunami of Sumatra Earthquake in 2004. The following discussions are based on his method.

Tsunami force acting to a bridge girder can be treated as a hydro dynamic force indicated by Eq.1, while the resistance of girder is mainly due to self weight computed by Eq.3 or Eq.4. The difference between Eq.3 and Eq.4 lies in the existence of buoyancy judging from the comparison of girder height with tsunami height. Eq.3 should be used when a bridge girder is not submerged at the attack of tsunami, while Eq.4 is for the case of bride girder being submerged and having buoyancy at tsunami.

$$
F=\frac{1}{2} \rho_{w} C_{d} v^{2} A_{h}
$$




$$
\begin{aligned}
C_{d} & =\left\{\begin{array}{ll}
2.1-0.1 \cdot(B / D) & (1<B / D<8) \\
1.3 & (8 \leq B / D)
\end{array}\right\} \\
S & =\mu W \\
S & =\mu(W-U)
\end{aligned}
$$

Where, $\rho_{\mathrm{w}}$ is density of water $\left(1030 \mathrm{~kg} / \mathrm{m}^{3}\right) ; \mathrm{C}_{\mathrm{d}}$ is the drag coefficient with its value decided based on reference (Japan Road Association, 2002), B and D are width and depth of girder; v is tsunami velocity $\left(6.0 \mathrm{~m} / \mathrm{s}\right.$ is used based on surveys of the Tohoku area); $A_{h}$ is the projected pressure area of the girder in the horizontal direction; $\mu$ is friction coefficient $(0.6$, based on research by Rabbat et al. (1985)); W is the girder's self weight $(\mathrm{kN})$, and $\mathrm{U}$ is buoyancy $(\mathrm{kN})$ as computed by Eq. 5 .

$$
U=\rho_{w} g V
$$

Where, $\mathrm{V}$ is volume of the bridge girder inner the tsunami $\left(\mathrm{m}^{3}\right)$.

The ratio of girder resistance $(\mathrm{S})$ to tsunami force $(\mathrm{F})$ is an index to judge whether a bridge girder is washed away or not by tsunami. The indicator $\beta$ is introduced in this paper as shown in Eq. 6 .

$$
\beta=\frac{S}{F}
$$

When $\beta$ is smaller than 1.0, a bridge girder has a great possibility of being washed away by a given magnitude of tsunami. Although the velocity of tsunami is most important in this study, observe records of velocity of tsunami are very few at the site of bridge. In this study, some recorded videos throughout the Tohoku area were used for determination of velocity. The average value of velocity is taken as $6.0 \mathrm{~m} / \mathrm{s}$ based on the research by Fu et al. (2012) and this value is used for analysis.

For evaluation of Eq.6 with comparison of the actual behavior of bridge girder, the observed condition of girder is defined as shown in Table 2. Three levels are introduced; Rank A (completely washed away) to Rank C (slightly damaged).

Fig.3 illustrates the computed $\beta$ values for 37 different types of girders. In general, girders having the $\beta$ value being larger than 1.5 are categorized in Rank $\mathrm{C}$ while girders with $\beta$ being smaller than 0.6 suffered the damage in Rank A.

Table 2: Definition of damage of bridge girder

\begin{tabular}{|c|c|}
\hline $\begin{array}{c}\text { Damage } \\
\text { level }\end{array}$ & $\begin{array}{c}\text { Observed condition of } \\
\text { superstructure }\end{array}$ \\
\hline Rank A & Washed away \\
\hline Rank B & $\begin{array}{c}\text { Moved but not fallen from } \\
\text { abutment }\end{array}$ \\
\hline Rank C & Slightly damaged \\
\hline
\end{tabular}




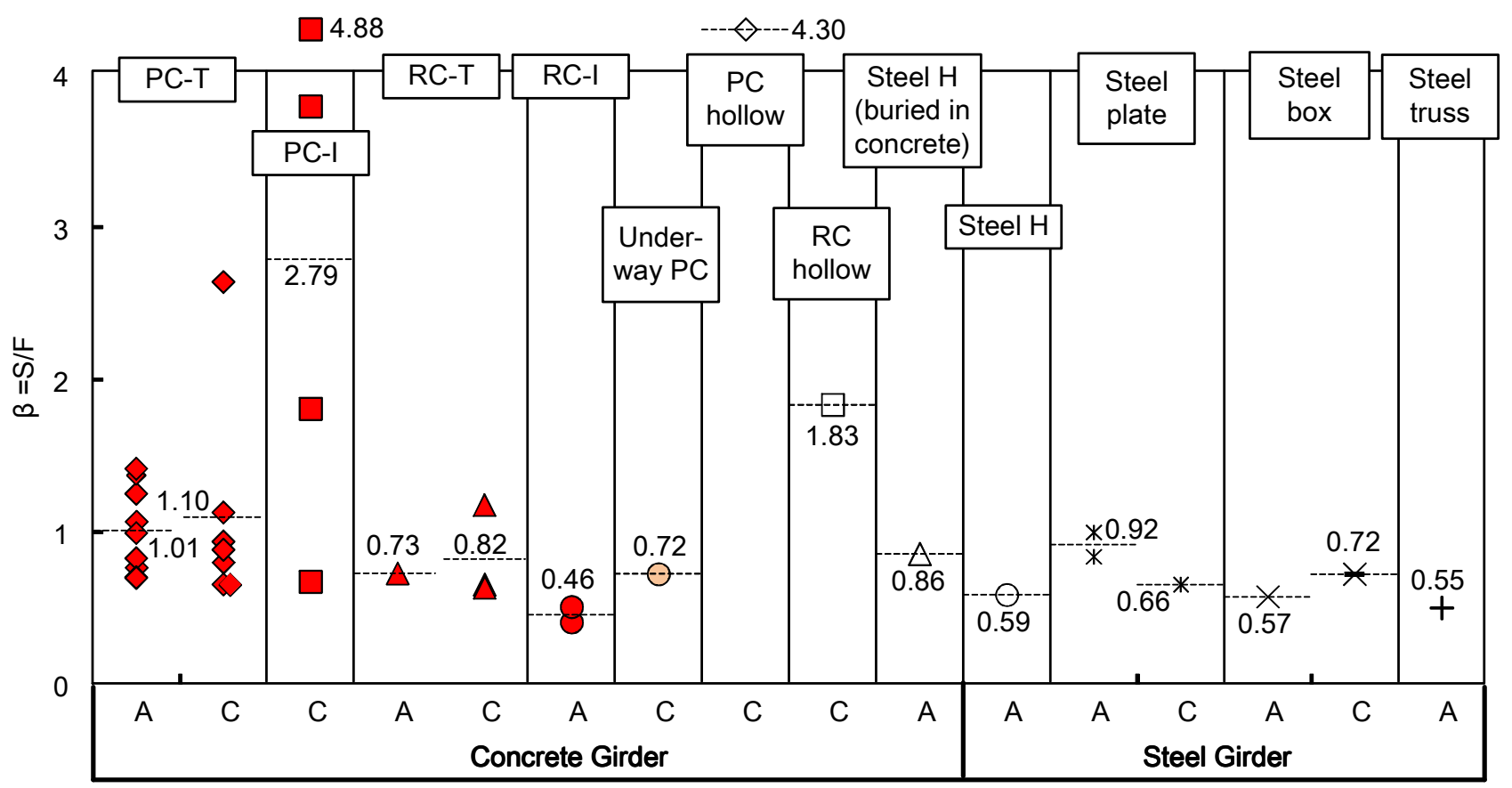

Figure 3: Classification of $\beta$ by girder type

There observes some girders survived (in Rank $C$ ) having $\beta$ values being less than 1.0. In the previous research works done by Kosa et al. (2010); Zheng et al. (2012), obvious differences are recognized in the value of $\beta$ for Rank A and Rank C. Types of girders were examined and a general tendency is drowned such that girders having relatively low height and wider width of cross section show higher resistance against tsunami. In addition, the height of pier should play an important role because the velocity of tsunami is a function of tsunami height. In this discussion the tsunami velocity was assumed as $6.0 \mathrm{~m} / \mathrm{s}$. Although further development is necessary, the $\beta$ value defined here could be effective to evaluate how much safe a bridge girder is against tsunami.

\section{CHARACTERISTICS OF TSUNAMI IN THE CITY ( SHIZUGAWA )}

Japan Meteorological Agent keeps observation of earthquakes and tsunamis constantly at certain points in Japan. The equipments to measure tsunami height and velocity, however, are set in the sea, not inland. The agent does not have any records of tsunami velocity in residential areas. Fortunately, some citizens have taken motion pictures of tsunami in the city by digital cameras.

Based on the motion pictures taken by citizens, the characteristics of tsunami in the city are able to be analyzed. Fig.4 shows the side view of Hachiman Bridge in Shizugawa area in Minamisanriku-Chou, Miyagi prefecture. Both cameras were focused on the bridge named Hachiman Bridge. Fig.5 shows a picture cut out from the recorded motion pictures at 7.05 second. In advance of picture analysis, key reference height is estimated as follows; (a) the height from the top of guardrail to static water level was $5.7 \mathrm{~m}$, (b) the height from the top of building-(a) to the top of guardrail was $5.9 \mathrm{~m}$, (c) the height from the top of guardrail to the window of building-(a) was about $2.0 \mathrm{~m}$. 


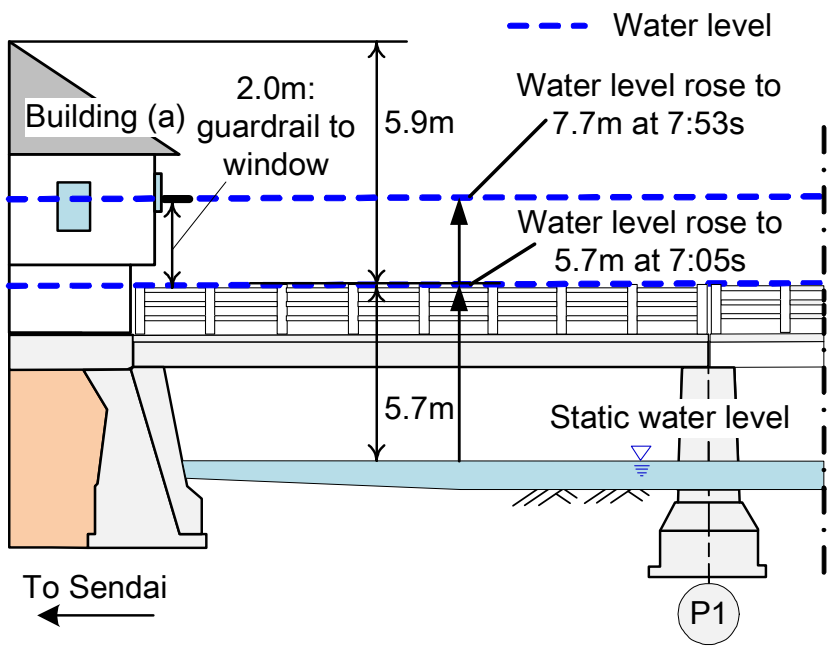

Figure 4: Side view of Hachiman bridge

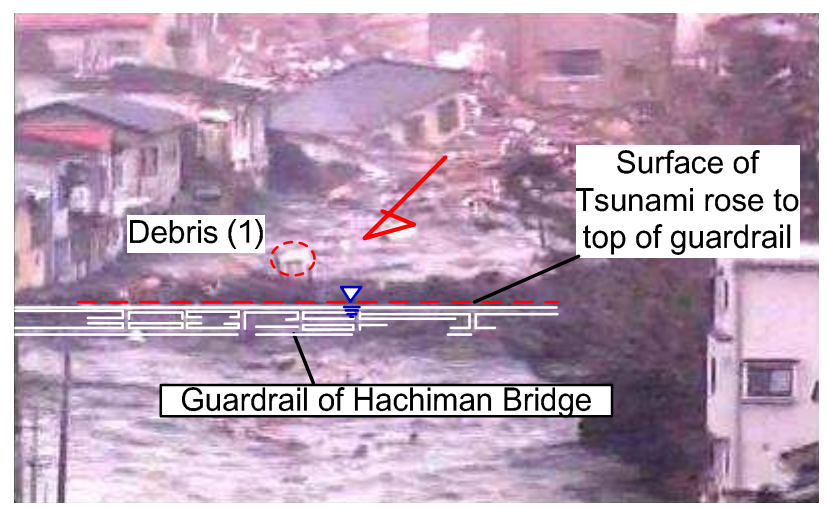

Figure 5: Shot of tsunami wave at Hachiman bridge

The analysis of tsunami is done in such a way that the surface of tsunami reached the top of guardrail at 7:05 second of motion picture, meaning that the tsunami height was $5.7 \mathrm{~m}$. The surface of tsunami reached the window of a house at 7:53 second, meaning that the tsunami height was 7.7 $\mathrm{m}$. Comparing these two set of data, the rising speed of tsunami can be determined. Motion picture analysis tells that the tsunami height rose with the speed of $3.19 \mathrm{~m} / \mathrm{min}$ at a time of 4 minutes after the hit of tsunami on Hachiman bridge, and that the tsunami ran up to the maximum $14.8 \mathrm{~m}$ high at $7 \mathrm{~min}$. after the hit, at a rising speed of $1.1 \mathrm{~m} / \mathrm{min}$. The average rising speed of tsunami height is estimated to be $2.24 \mathrm{~m} / \mathrm{min}$. It was relatively low speed, inferring that the wave shape was not the bore type.

There observed much debris flowing in the picture. These are good references to measure the velocity of tsunami. For example, take debris (1) and debris (2) in the motion picture and trace them with a certain time interval shown in the picture. Accurate distance of debris move can be confirmed by both internet media and on site survey.

By the above mentioned process, the wave height and velocity of tsunami can be estimated. Based on the analyzed results the relationship between tsunami height and tsunami velocity is obtained and shown in Fig.6. In the figure the assumption that the velocity should be 0 when the tsunami height is 0 is added. When the tsunami began to fall back, the velocity was treated as 0 as well. Before the tsunami reached about $2 \mathrm{~m}$, the tsunami velocity rose to about $6 \mathrm{~m} / \mathrm{s}$.

The velocity of tsunami increased continually before the tsunami wave hit the bridge girder. The maximum velocity is estimated as $7.02 \mathrm{~m} / \mathrm{s}$ just before the tsunami wave reached the bridge girder. When the tsunami wave ran up to about $6 \mathrm{~m}$ high, the bridge gird3er began to be inundated and the tsunami velocity got to decrease to about $4.86 \mathrm{~m} / \mathrm{s}$. After the tsunami height reached about $12 \mathrm{~m}$, the velocity decreased to 0 gradually. 
Fig.6 tells two things. Firstly, the tsunami velocity continuously increases up to the maximum before the tsunami begins to overflow the bridge girder. Secondly, the tsunami velocity decreased suddenly when the bridge girder is inundated. In addition, Hachiman Bridge has a local geographical feature showing that the level of girder is the same as the level of embankment. When the tsunami height rises up to the level of girder, the tsunami would overflow to the land area and that results in the reduction of tsunami energy and velocity.

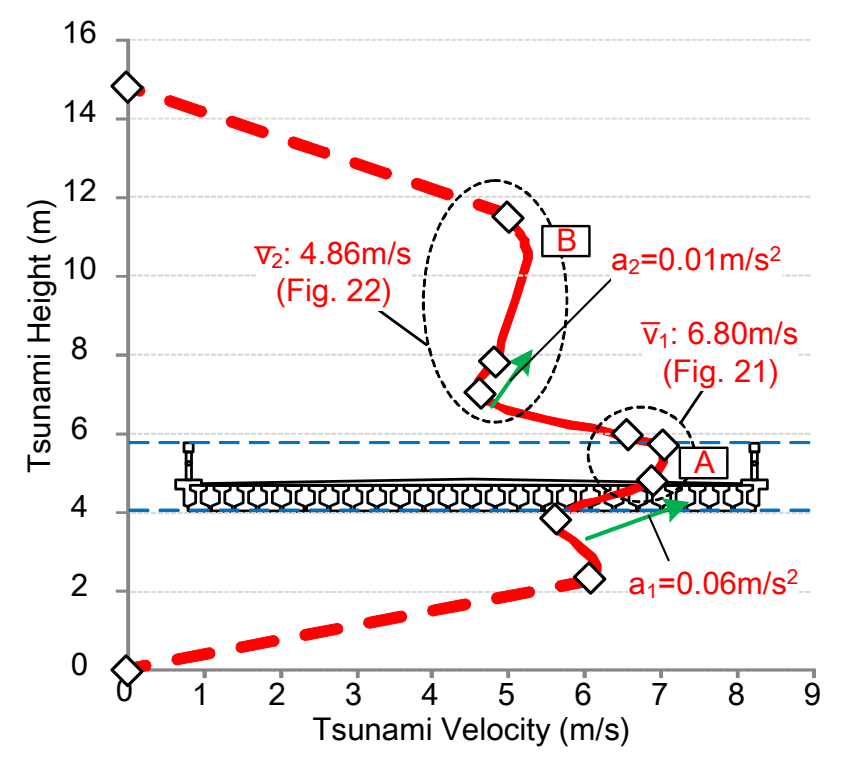

Figure 6: Time-depended Variation of Tsunami Height

\section{EXPERIMENTAL EXAMINATION AND SIMULATION}

In the previous section the $\beta$ value is introduced to consider the resistance of bridge girder against tsunami. The $\beta$ value counts only the horizontal force by tsunami. Field survey, however, indicates the existence of up-lift force due to tsunami. Some bridge girders were washed away without any damage of anti-fallen device provided at the head of piers. Necessary modification for the $\beta$ value is to introduce the influence of up-lift force. Experimental works were conducted to examine the mechanism of production of up-lift force on bridge girders during tsunami.

Using relatively large water channel which enable to realize 1/10 scale model of bridge girder, the influence of tsunami velocity, water depth as well as existence of solitary wave as shown in Figs.7 and 8 were examined in terms of up-lift force.

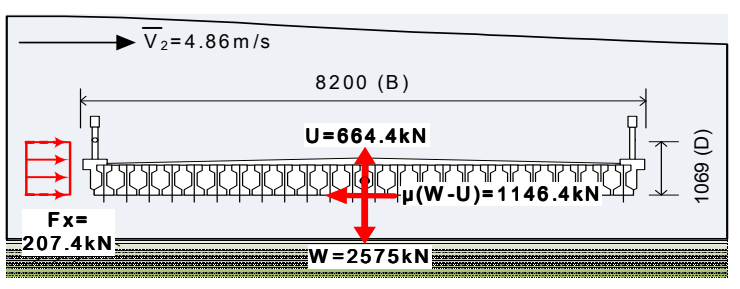

Figure 7: Uniform flow

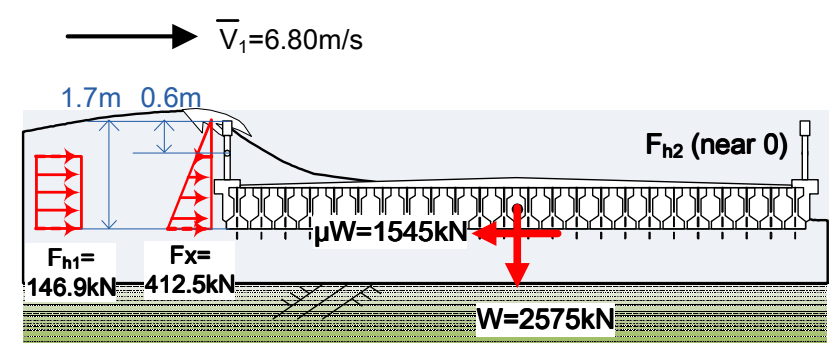

Figure 8: Solitary wave 
Table 3: Experimental parameters

\begin{tabular}{|c|c|c|c|}
\hline \multicolumn{2}{|c|}{ Uniform flow } & \multicolumn{2}{|c|}{ Solitary wave } \\
\hline $\begin{array}{l}\text { Initial water depth } \\
{[\mathrm{m}]}\end{array}$ & Velocity $[\mathrm{m} / \mathrm{s}]$ & $\begin{array}{l}\text { Initial water depth } \\
{[\mathrm{m}]}\end{array}$ & Wave height[m] \\
\hline 1.33 & $1.6 \sim 1.8$ & 1.22 & $0.20 \sim 0.40$ \\
\hline 1.43 & $1.6 \sim 1.8$ & 1.33 & $0.20 \sim 0.50$ \\
\hline 1.53 & $1.4 \sim 2.0$ & 1.43 & $0.20 \sim 0.50$ \\
\hline 1.63 & $0.7 \sim 1.7$ & \multicolumn{2}{|l|}{$\underline{\nabla} 173 \mathrm{~mm}$} \\
\hline 1.73 & $1.0 \sim 1.5$ & \multicolumn{2}{|c|}{ 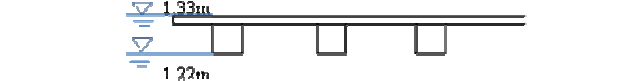 } \\
\hline
\end{tabular}

The size of water channel was $10 \mathrm{~m}$ of width, $4.6 \mathrm{~m}$ of depth and $50 \mathrm{~m}$ of length. Two pumps were provided to supply water of $284 \mathrm{~m}^{3} / \mathrm{min}$. The model scale is $1 / 10$, and on the girders, wave pressure gauges and pour water pressure gauges were installed at 40 locations on the front surface, back surface, top surface, and bottom surface of the girders.

Table 3 shows parameters in this study. The height of model girder is $1.33 \mathrm{~m}$. In the case of uniform flow, the height of water flow increases by $0.10 \mathrm{~m}$ incrementally. In some cases the velocity of flow is varied by change of amount of water supply. The listed velocity in table 3 was measured ones since flow velocity was not accurately controlled. In the case of solitary wave, basic wave height is $0.20 \mathrm{~m}$ and the wave height increases by $0.10 \mathrm{~m}$ incrementally. The initial water depth varies from 1.22 to 1.43 . The flow velocity was $1.0-1.5 \mathrm{~m} / \mathrm{s}$.

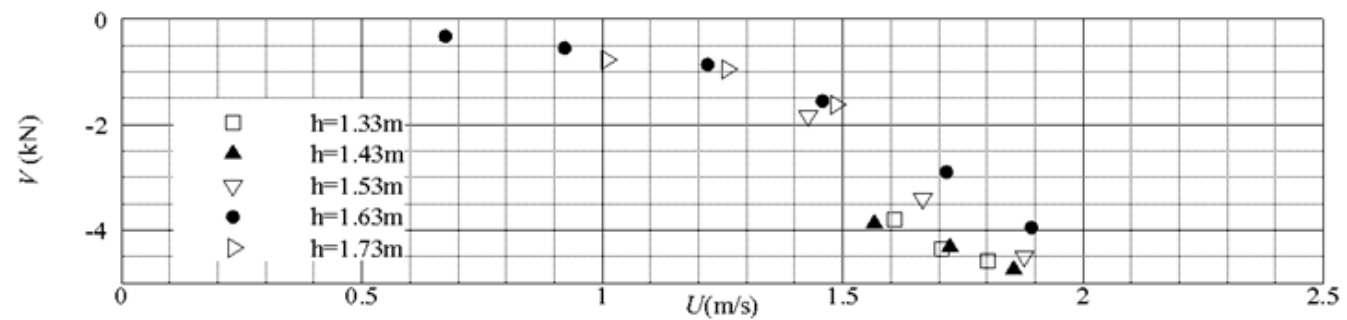

Figure 9: Up-lift force (uniform flow)

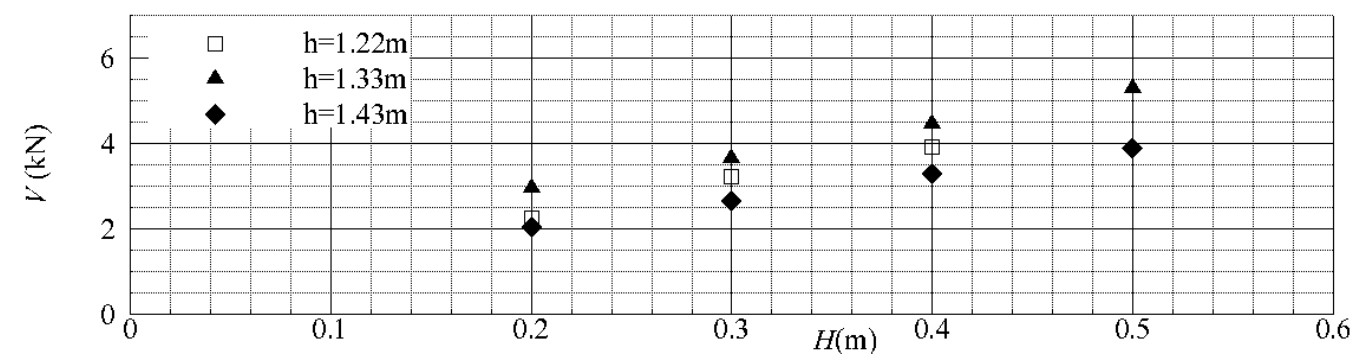

Figure 10: Up-lift force (solitary wave) 
Test results are shown in Figs. 9 and 10. The up-lift force was calculated based on the measured water pressure. In the case of uniform flow, up-lift force was measured negative in all cases. That means a girder was pushed downward. There was no observation of girder washed away. In the case of solitary wave, a girder was observed washed away in 6 cases. A girder was easy to be washed away when the initial water depth was equal to or less than the girder height and the wave height was large enough to up-lift the girder.

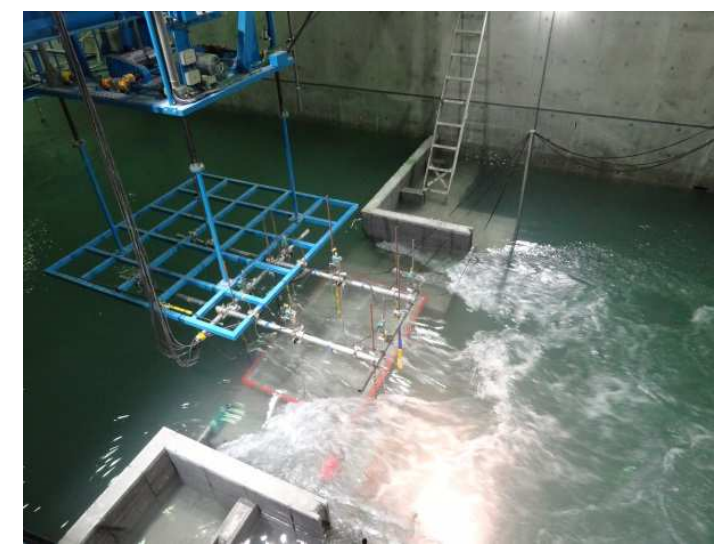

Figure 11: Girder under uniform flow

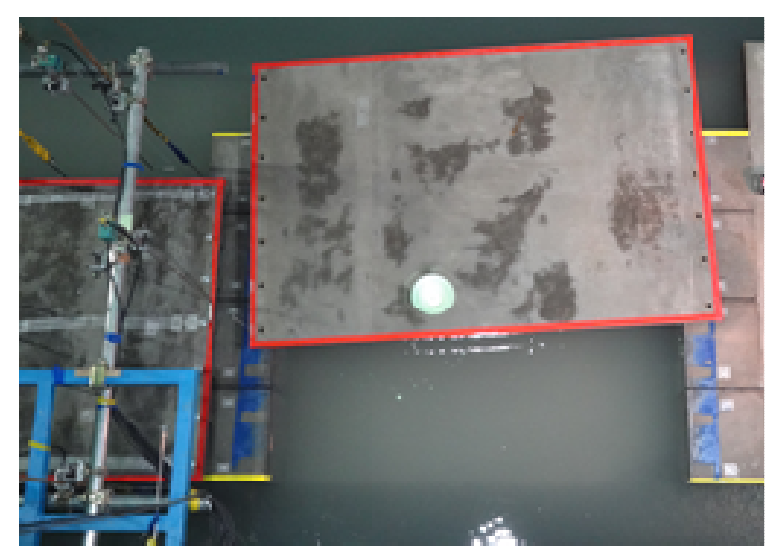

Figure 12: Moved girder under solitary wave

Figs. 11 and 12 show pictures of girder in the experiment. Uniform flow could not move a girder even at a large velocity while solitary wave could lift and move a girder.

A simulation model has been developed by one of the authors to study experimental results in details (Nakamura et.al 2011, 2013). Some figures are shown in Figs. 13 and 14. It needs further development to simulate test results, but this work could give deeper understandings on the mechanism of a bridge washed away by tsunami, and result in proper evaluation of tsunami force in design of bridge.

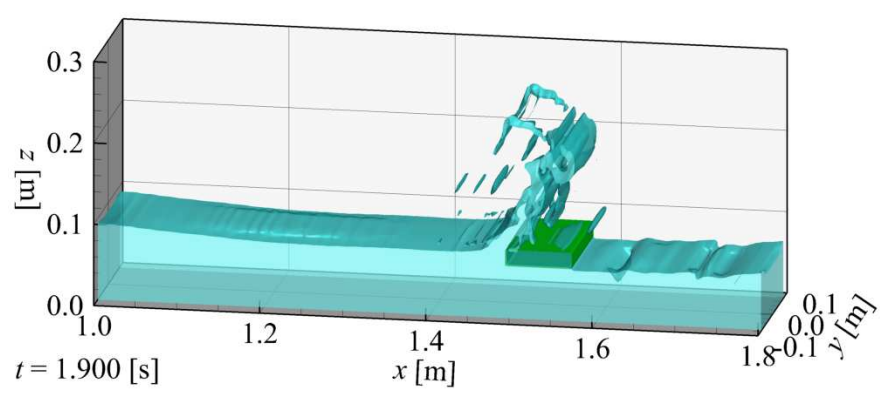

Figure 13: Graphic simulation

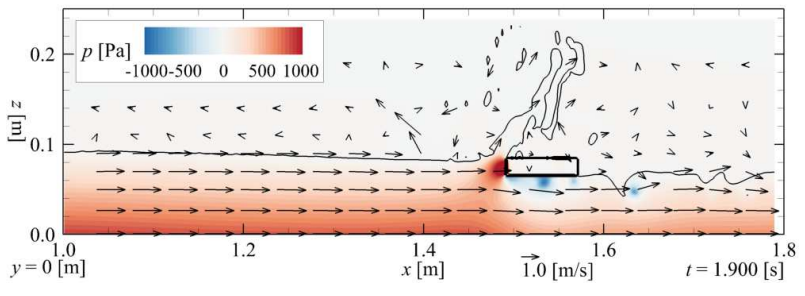

Figure 14: Numerical results

\section{CONCLUSIONS}

The research work in the paper covers the field survey of damage of bridges by the tsunami on March 11, 2011, the damage analysis based on database, the characteristic of tsunami after coming up the land, and the hydraulic experiment with development of numerical simulation technique. The followings are concluded. 
(1) Internet media is a powerful tool to survey the damage by tsunami in wide area.

(2) More than 200 out of 1793 bridges in the inundation area of east Japan (Tohoku region) were washed away by the tsunami. Comparing survived bridge girders with washed ones, girders with rather shallow cross sections are observed much resistive against tsunami.

(3) Water pressure acted on bridge girder may be evaluated by proposed $\beta$ value. The location of bridge and the height of pier might influence the condition of girder at the attack of tsunami.

(4) The velocity of tsunami in the land increases linearly as the height of tsunami increases.

(5) Experimental examination reveals that a solitary wave produces up-lift force on a bridge girder. On the other hand, uniform flow eventually causes force to push a girder to abutments.

\section{ACKNOWLEDGMENTS}

A part of this study was conducted by the support of JSPS Grant-in-Aid for Scientific Research (A) 24246079. The authors acknowledge the support very much. The authors' thanks are extended to the assistance of Mr. Takuya Shiraishi, a graduate student at Nagaoka University of Technology, and Mr. Yutaro Sawa, an undergraduate student at Nagoya University.

\section{REFERENCES}

Fu L., Kosa, K., Hedeki, S., and Zheng, Y.(2012). Damage to Structures due to Tsunami and Evaluation of Tsunami Velocity in Shizugawa, Proc. of JCI. Vol.34, pp. 805-810

Graduate School of Resource Sciences of Department of Civil and Environmental Engineering of Akita University (2011).,Survey of bridge structures of Miyagi Prefecture, Apr. 2011, (http://www.str.ce.akita-u.ac.jp/br/miyagi_str.html)

Japan Road Association (2002), Specifications for Highway Bridges Part I Common, pp. 52-57

Kosa, K., Nii, S., Shoji, G. and Miyahara, K. (2010), Analysis of Damaged Bridge by Tsunami due to Sumatra Earthquake, Journal of Structural Engineering, JSCE, Vol. 55A, pp. 454-463 (in Japanese).

Komatsu, T., Ogushi, K. (2011), Newly Organized Hydraulics, Rikotosho, Apr., pp. 9-12

Maruyama, K., Tanaka, Y., Kosa, K., Hosoda, A., Mizutani, N. and Nakamura, T.(2013), Evaluation of Tsunami Force acted on Bridges by Great East Japan Earthquake, 10th International Conference on Urban Earthquake Engineering, Reg. \#20-385, pp.7-16

Nakamura, T., Yim, S. C., and Mizutani, N.(2011). Numerical simulation on local scouring around bottom-mounted movable short cylinder, Proc., Coastal Structures 2011, ASCE, C4-087, 12 pp.

Nakao, H., Izuno, K., and Kobayashi, H.(2010). Study on relation of velocity and wave height to hydrodynamic force on bridges by tsunami, J. Structural Eng., JSCE, Vol. 56A, pp. 564-575 (in Japanese).

Rabbat, B.G. and Russel, H.G.(1985), Friction coefficient of steel on concrete or grout, Journal of Structural Engineering, ASCE, Vol. 111, No. 3, pp. 505-515

Zheng, Y., Kosa, K., Hideki, S., Fu, L.(2012), Damage to Structures in Rikuzentakata Region Due to Tsunami, Proc. of JCI. Vol.34, pp. 811-816 